\title{
EDUCAÇÃO AMBIENTAL CRÍTICA EM UM CURSO TÉCNICO EM EDIFICAÇÕES: O USO DE TIRINHAS COMO CONTEXTUALIZAÇÃO DO MUNDO DO TRABALHO
}

\author{
Denise Santos Nascimento*, Marcus Vinicius Pereira \\ E-mail*: nise.poli@gmail.com \\ Instituto Federal de Educação, Ciência e Tecnologia do Rio de Janeiro \\ DOI: $10.15628 /$ rbept.2020.11336 \\ Artigo submetido em: out/2020 e aceito em: dez/2020
}

\begin{abstract}
RESUMO
A inserção de uma nova ferramenta de ensino na disciplina de projeto final de um curso técnico em edificações noturno, localizado na cidade de Mesquita (Baixada Fluminense do RJ) foi objeto desta pesquisa, que buscou analisar a contribuição didática do uso de tirinhas como um contextualizador do mundo do trabalho para promoção do raciocínio crítico sobre a construção civil e a educação ambiental. Trata-se de uma pesquisa desenvolvida com estudantes por meio de oficinas durante três meses. O material produzido foi analisado e deu origem a um encarte de tirinhas e a uma sequência didática. Foi possível estabelecer uma relação dialógica, prática e participativa, considerando as histórias de vida, experiências pessoais e de familiares dos estudantes, e as relações entre o curso técnico em edificações, a crise educacional, a violência, a falta de emprego e a relação com o meio ambiente.
\end{abstract}

Palavras-chave: Educação ambiental crítica. Quadrinhos. Tirinhas. Educação profissional técnica. Edificações.

\section{CRITICAL ENVIRONMENTAL EDUCATION IN A TECHNICAL COURSE IN BUILDINGS: THE USE OF COMIC STRIPS AS CONTEXTUALIZATION OF THE WORLD OF WORK}

\begin{abstract}
The object of this research is the insertion of a new teaching tool in the final project subject of a technical night course in buildings, located in the city of Mesquita (Baixada Fluminense of Rio de Janeiro state). We sought to analyze the didactic contribution of using comic strips as a contextualizer of the world of work to promote critical thinking about construction and environmental education. It is a research developed with students through workshops for three months. The material produced was analyzed and gave rise to a booklet of strips and a didactic sequence. It was possible to establish a dialogical, practical and participative relationship, considering the students' life stories, personal and family experiences, as well as the relationship between the technical course in buildings, the educational crisis, violence, the lack of employment and the relationship with the environment.
\end{abstract}

Keywords: Critical environmental education. Comics. Comic strips. Technical professional education. Buildings. 


\section{INTRODUÇÃO}

A necessidade de uma abordagem mais crítica e dialética nos entendimentos sobre construção civil e questões ambientais junto com as dificuldades enfrentadas em sala de aula para fazer com que alunos abandonem conceitos ultrapassados, ingênuos e equivocados sobre as fundamentam a motivação do trabalho presente neste artigo. Temos como cenário empírico a disciplina projeto final de um curso técnico em edificações de um Centro Vocacional Tecnológico (CVT) localizado no município de Mesquita, que pertence à Região Metropolitana do Estado do Rio de Janeiro. Seu público é composto por jovens de classe baixa que buscam uma profissão e também por profissionais que já exercem atividades na área da construção civil, buscando melhorar suas condições de trabalho. Mesmo com diferentes perfis, não é diferente a visão reducionista que eles costumam ter da Educação Ambiental (EA), em geral relacionada à reciclagem, ao aproveitamento de água da chuva e ao uso de painéis de luz solar. Não possuem uma clara compreensão sobre a relação da construção civil com a EA, tampouco uma visão social crítica sobre o assunto.

Isso se reflete também no Currículo Mínimo do Governo do Estado do Rio de Janeiro (2011), que é vago no que diz respeito às questões ambientais e à responsabilidade da construção civil. Na formação do profissional técnico em edificações (ou mesmo nos cursos livres de pedreiro), não se pode limitar em apenas citar "soluções sustentáveis", como painel solar e captação de água da chuva para as edificações. É preciso enxergar esse sujeito como alguém responsável por pequenas construções na região onde reside, sobretudo nesse CVT, onde considerável parte das construções são realizadas por esses futuros profissionais, sem a presença de arquitetos ou engenheiros, em que deve ser capaz de não somente usar inovações construtivas de menos impacto ambiental, mas também criar suas próprias soluções, refletindo sobre as reais consequências das suas ações, da empresa em que trabalha e das políticas do governo. É esperado que esse profissional consiga analisar questões mais complexas e que não espere inovações tecnológicas salvacionistas e nem aceite a culpabilização do trabalhador sem levar em consideração o mundo da produção e do consumo do modo capitalista.

Desta forma, para essa pesquisa foram criados personagens que exemplificassem o mundo do trabalho da construção civil, tanto na elaboração dos projetos e licenças (escritório) quanto na execução (canteiro de obras), configurando-se como parte do produto educacional associado a dissertação de mestrado profissional da primeira autora. Trata-se de proposta de utilização da História em Quadrinhos (HQ) como contextualização do mundo do trabalho em que diversas situações podem ser criadas, possibilitando uma melhor visualização da realidade pelo aluno que não possui ainda experiência 
profissional, assim como, por aquele que já possui alguma experiência e possa se identificar com as situações apresentadas.

Como pressuposto, consideramos que ao usar uma estratégia didática sob um aspecto lúdico e estético como a criação de tirinhas (que são uma modalidade de $\mathrm{HQ}$ ), o aluno pode ser motivado, despertando seu interesse ao interagir com as narrativas e os conceitos desenvolvidos nas aulas. Isso pode levar a uma melhor compreensão sobre a EA na construção civil e, com isso, os trabalhos desenvolvidos ao longo do curso possam refletir uma evolução crítica do aluno, além de possibilitar a sua sensibilização como um cidadão mais consciente do seu papel no mundo do trabalho da construção civil.

Outro fator importante é que, antes da realização desta pesquisa, a EA aparecia nas aulas apenas nas questões técnicas atribuídas à gestão ambiental e ao conforto ambiental, e agora espera-se que ela atue como uma teia, unindo e fazendo parte de todos os assuntos abordados do curso. Assim, a abordagem crítica contribui para que o aluno se reconheça como parte de um sistema complexo, e, com isso, interaja de forma mais realista com as questões ambientais. Nosso objetivo é verificar a contribuição didática do uso de tirinhas como contextualização do mundo do trabalho para promover 0 raciocínio crítico sobre a relação da construção civil com a educação ambiental.

\section{EDUCAÇÃO AMBIENTAL E PRÁTICA PROFISSIONAL CONSCIENTE}

As questões ambientais vêm sendo discutidas há muito tempo, mas ao observarmos a forma que a população reflete sobre essas questões, parece que ainda não nos encontramos nos discursos oferecidos, como se na realidade tudo o que foi dito e observado sobre a contínua degradação ambiental não afetasse a vida do homem no mundo. Um exemplo dessa alienação é o consumismo. Os padrões mundiais de consumo mudaram para quase um único padrão, em que oriente e ocidente desejam as mesmas coisas, a mesma casa, os mesmos móveis, o mesmo celular. Bens materiais são exibidos em perfis das redes sociais mostrando a principal característica da atual geração: o poder de consumo. Essa situação leva ao consumo de massa em alguns lugares do mundo enquanto cresce exponencialmente as pessoas desempregadas e desalentadas, e ambas se relacionam a questões ambientais (DELUIZ; NOVICKI, 2004, p.2).

As questões do consumo excessivo não parecem ser prioridade e perdem sempre para eficiência e inovações tecnológicas para um desenvolvimento sustentável como se os problemas ambientais mais tivessem a ver com nossa falta de entendimento sobre o funcionamento da natureza. No entanto, talvez o mais grave seja o fato de mesmo sem ser a principal ação a ser combatida para melhorar as condições ambientais atuais, chega-se ao ponto de muitos governantes fazerem o contrário, incentivá-la. Mudanças já 
aconteceram para promoção de um desenvolvimento sustentável, leis foram criadas para exigir responsabilidades de empresas, subsídios para municípios que melhorem sua gestão ambiental, EA nas escolas e veículos de comunicação. Porém, o tripé social, ambiental e econômico da sustentabilidade muitas vezes tende para um lado só, principalmente quando atrelado ao desenvolvimento. Empresas agem segundo seus interesses econômicos, municípios ficam atentos apenas aos subsídios e uma EA que mais aliena do que faz o cidadão refletir sobre os problemas socioambientais. Soma-se a isso o agravante de corrupção no Brasil sem o menor constrangimento e a menor importância para questões ambientais. Não é incomum tomarmos conhecimento de políticos que usam para benefício próprio dinheiro público destinado à infraestrutura e saneamento, fazendo piorar a situação dos rios, mares e solos. Não obstante, também não é incomum a existência de escolas que têm projetos político-pedagógicos que afirmam ser pautados em Paulo Freire quando, de fato, desenvolvem uma EA alienadora, responsabilizando o cidadão com medidas individuais, sem a devida reflexão política, sem problematizar o consumismo e o poder exagerado das empresas.

Com o costume de usar as soluções de gestão ambiental nas aulas e vislumbrando na abordagem crítica a dificuldade de ver um fim, pois com a abordagem crítica essas respostas não são dadas, reflexões são feitas e muitas vezes um incômodo é o que fica no final da discussão em sala de aula. Mas a seguir, buscou-se entender esse questionamento eterno e crítico para uma aplicação em sala de aula com realidades advindas de um grupo sem privilégios que busca seu sustento nas áreas da construção civil. Para iniciarmos essa abordagem crítica socioambiental do desenvolvimento sustentável, fazemos uma volta à história a fim de destacar pontos importantes para a EA, que teve por base duas publicações: "Educação ambiental. Vinte anos de políticas públicas" da Secretaria de Meio Ambiente de São Paulo (2003) e "Os diferentes matizes da educação ambiental no Brasil" do Ministério do Meio Ambiente (2009). Por outro lado, nos últimos 50 anos de acontecimentos e políticas sobre EA, constata-se que as questões ambientais não melhoraram, pelo contrário. Estamos sem definições efetivas para um nível mundial e, no Brasil, temos um governo que deixa claro que as questões ambientais não são prioridades. Isso nos faz refletir sobre a questão da educação como "um direito e uma estratégia de investimento do Estado" (FRIGOTTO; CIAVATTA, 2003, p.52), e que o problema da EA seja uma estratégia de governo e até em um nível mundial se pensarmos nas atitudes tomadas pelos governos dos países considerados desenvolvidos.

Partindo do ponto que a EA trabalhada nesta pesquisa deva ser a mais libertadora possível, ainda mais em uma escola inserida em uma região pobre com diversos problemas sociais, aderimos a ideia de que ela precisa promover uma abordagem crítica que possibilite trabalhar para além do conceito reducionista. Para definir o que trata uma Educação Ambiental Crítica (EAC), precisamos compreender que no cenário atual, segundo Loureiro e Layrargues 
(2013), a EA compreende três macrotendências: conservacionista, pragmática e crítica. Para esses autores, a conservacionista e a pragmática estão apenas em momentos temporais diferentes: a abordagem pragmática é a abordagem conservadora se adaptando ao longo do tempo às novas tecnologias, políticas e governos. Essa abordagem está relacionada a uma prática sem reflexão das questões sociais, agindo muitas vezes como fonte de alienação e manipulação da população. Vendem a ideia de uma possível solução tecnológica salvacionista para a natureza, como se os problemas ambientais existissem apenas por ainda não haver a "tecnologia correta" para solução deles.

A macrotendência crítica possui uma abordagem de forte questionamento social, em que os problemas ambientais são vistos como consequência de um sistema que incentiva o consumo. Para a EAC, a solução das questões ambientais está ligada a uma mudança de sistema, já que não é possível que os recursos naturais suportem o modo de produção capitalista.

Para a macrotendência crítica, não basta lutar por uma nova cultura na relação entre o ser humano e a natureza; é preciso lutar ao mesmo tempo por uma nova sociedade. Não se trata de promover apenas reformas setoriais, mas uma renovação multidimensional capaz de transformar o conhecimento, as instituições, as relações sociais e políticas, e os valores culturais e éticos. Trata-se de incluir no debate ambiental a compreensão político-ideológico mecanismos da reprodução social e o entendimento de que a relação Ecologia política, justiça e educação ambiental crítica: perspectivas de aliança contra-hegemônica entre o ser humano e a natureza é mediada por relações socioculturais e classes historicamente construídas. (LOUREIRO; LAYRARGUES, 2013, p. 66).

Entendendo a necessidade de uma abordagem crítica e partindo para uma congruência com o cenário atual, encontramos na linha do tempo informações que mostram que as principais conferências e debates acerca das questões ambientais nos últimos anos trazem uma tendência à promoção do desenvolvimento sustentável como meta de solução das questões ambientais. Para tal, a gestão ambiental e a educação ambiental são eleitas como instrumentos para atingir o objetivo do desenvolvimento sustentável. Essa meta deixa espaço para diversas interpretações, como o fato das questões ambientais serem apenas um detalhe em uma política que diz querer solucionar seus problemas. Outra questão importante diz respeito ao próprio termo desenvolvimento sustentável, termo ambíguo de impossível mensuração, pois não deixa clara a ideia de que os recursos naturais são finitos, levando a uma compreensão equivocada, como observa Bomfim (2010, p.3-4): 
porque da forma que esse conceito vem sendo utilizado nos últimos anos, tornou-se um oxímoro (como entrar-sair, escuroclaro), tornou-se uma justaposição inconciliável entre duas palavras, no caso: "Desenvolvimento" e "Sustentável". Tudo que se fala a respeito de "responsabilidade ambiental", "consciência ecológica", "áreas de preservação", "políticas verdes", etc. não conseguem impedir a destruição da natureza, em nome do desenvolvimentismo.

Mesmo com tantos questionamentos, o desenvolvimento sustentável é uma realidade, o termo fixou e está diretamente ligado à construção civil. Os termos relativos ao desenvolvimento sustentável como casa verde, edifícios eficientes, edifícios sustentáveis, telhas sustentáveis, instalações eficientes, são apenas alguns chavões da atual arquitetura sustentável e da construção sustentável. Exatamente por não se ter uma definição muito concreta do que seja o desenvolvimento sustentável, surgem tantos termos correlatos, como aponta Acselrad (2001, p. 8) para várias expressões com distintas representações e valores que são associados ao discurso da sustentabilidade.

O desenvolvimento sustentável se divide em três matrizes teóricas segundo Deluiz e Novicki (2004), que informam a intenção de efetivar distintos projetos políticos, a saber: matriz da eficiência, matriz da autossuficiência e matriz da equidade. A matriz da eficiência do desenvolvimento sustentável é descrita como sendo aquele que atende às necessidades do presente sem comprometer a possibilidade de as gerações futuras atenderem às suas próprias necessidades, entendendo que as questões ambientais podem ser resolvidas com o desenvolvimento tecnológico, e uma gestão ambiental bem feita poderá garantir os recursos para o futuro. Esta matriz teórica permite que se sobreponha as questões econômica do tripé da sustentabilidade em primeiro lugar, dando espaço também ao lucro com a própria atitude em se fazer o "ambientalismo", como as cotas de carbono, soluções ecológicas e selos verde. É a matriz que Deluiz e Novicki (2004) chamam de mercadológicoambiental. A segunda concepção de desenvolvimento sustentável é orientada pela matriz discursiva da autossuficiência e propõe uma volta ao passado com o homem vivendo em função da natureza e se colocando em segundo plano. Uma matriz "biocêntrica" que entende que a sustentabilidade seria alcançada com a preservação e construção de comunidades sustentáveis, que desenvolvem relações tradicionais com o meio físico natural de que depende sua sobrevivência. A terceira concepção de desenvolvimento sustentável é orientada pela matriz discursiva da equidade, trazendo para discussão trabalho e natureza, e recebe o nome de "sustentabilidade democrática". Uma perspectiva em que o mercado deixa de ser um ator privilegiado, sendo realizada com a equidade das bases sustentáveis. Nessa concepção, as questões socioambientais estão diretamente ligadas às questões sociais, em um processo onde as sociedades administram seus recursos de forma ética. 
A sustentabilidade democrática está diretamente ligada à definição da EAC e tem como função chegar a mais radical transformação social possível para que as questões do mercado não se sobreponham às necessidades da população e, por conseguinte, às necessidades ambientais. A abordagem crítica que tanto buscamos pode, em muitos momentos, receber um viés holístico, que seria uma visão sistêmica das questões ambientais como um reflexo de tudo, que não deixa de conferir um olhar crítico. Entender como tudo está interligado nos coloca em outra posição em relação à natureza, de que estamos cuidando de nós mesmos e que não teria sentido nossa degradação. Contudo, sendo a meta das políticas ambientais vigentes a promoção do desenvolvimento sustentável e tendo como ferramentas a gestão ambiental e a educação ambiental, esta fundamentação teórica se esforça em fornecer subsídios para implantação de uma EAC, para promover a matriz de equidade sustentável (sustentabilidade democrática), articulando com um viés holístico. Deglutindo sobre tudo que foi exposto, podemos dizer que vivemos um paradoxo, sem sabermos onde realmente nos encaixamos: queremos sempre mais por estarmos incompletos, somos irmãos dos que nos exploram, acreditamos em discursos que nos manipulam e não temos o direito de uma atitude contrária senão ficamos a margem, marginalizados na nossa própria terra.

\section{TIRINHAS COMO CONTEXTUALIZAÇÃO DO MUNDO DO TRABALHO}

A arte sequencial, que engloba as tirinhas e as $\mathrm{HQs}$ foi um termo criado por Eisner (1989). Segundo ele, a tirinha pode ser definida como a arte sequencial que lida com a disposição de figuras ou imagens e palavras para narrar uma história ou dramatizar uma ideia. As tirinhas, tiras cômicas ou apenas tiras são, segundo Vergueiro e Ramos (2009), uma forma de piada relatada com os recursos das HQs. Essas piadas em quadros são recheadas de referências, costumam estar em linhas, ter poucos quadros, possuir uma mensagem rápida, com comicidade e sem a necessidade de textos para sua compreensão. Entendendo que as tirinhas pertencem ao mundo da arte sequencial, o uso do termo tirinhas será utilizado apenas quando se tratar especificamente do material finalizado do produto desta pesquisa, estando todo o restante nomeado de quadrinhos ou $\mathrm{HQ}$. Ao observarmos o atual cenário, o uso da arte sequencial vem conquistando grande espaço na educação, sendo encontrada em grande parte dos livros didáticos para contar uma história, em questões do Exame Nacional do Ensino Médio (ENEM), além de informativos de saúde e em outros locais e materiais com as mais diversas finalidades.

Mas esse avanço é recente! Os quadrinhos tiveram seu auge no fim do século XIX, impulsionado pela evolução da tipografia, mas ao longo dos anos foi marginalizado e censurado. No Brasil não foi diferente, quando, no período 
da ditadura, concebeu-se uma série de normas para sua criação e sua reputação não era das melhores, como apontam Rama e Vergueiro (2004, p. 16).

Apesar de sua imensa popularidade junto ao público leitor composto principalmente por jovens e adolescentes - e das altíssimas tiragens das revistas, a leitura de histórias em quadrinhos passou a ser estigmatizada pelas camadas ditas "pensantes" da sociedade. Tinha-se como certo que sua leitura afastava as crianças de "objetivos mais nobres" - como o conhecimento do "mundo dos livros" e o estudo de "assuntos sérios" -, que causava prejuízos ao rendimento escolar e poderia, inclusive, gerar consequências ainda mais aterradoras, como o embotamento do raciocínio lógico, a dificuldade para apreensão de ideias abstratas e o mergulho em um ambiente imaginativo prejudicial ao relacionamento social e afetivo de seus leitores.

Os quadrinhos eram muitas vezes vinculados à violência e foram perseguidos por anos. Haag (2005) revela detalhes dessa trajetória de perseguição aos quadrinhos no Brasil. Acontecimentos que passam por ataques de padres, que segundo ele "rezavam pela cartilha de Mussolini", por Carlos Lacerda, usando termos de "veneno importado para crianças" e "desnacionalização da juventude". Isso fez com que o Ministério da Educação divulgasse um estudo em que afirmava que a leitura de quadrinhos causava preguiça mental e desestimulava o aprendizado. Tanta perseguição tinha motivo: em 1960, chegava-se a vender 240 milhões de exemplares para uma população de 55 milhões. Esse mercado era sim usado por alguns grupos que expunham suas ideologias, mas era dominado mesmo por materiais importados por empresários em início de carreira, que viriam a se tornar grandes empresários da comunicação brasileira: Roberto Marinho, Adolfo Ãizen e Victor Civita.

Após o fim da ditadura, documentos oficiais da área educacional, como a Lei de Diretrizes e Bases da Educação, os Parâmetros e as Diretrizes Curriculares Nacionais, contribuíram para a merecida desmarginalização dos quadrinhos. Incluindo em seus textos o incentivo ao seu uso como ferramenta facilitadora do ensino, "de certa forma, propunha um pacto entre este produto midiático e a educação formal" (SANTOS; VERGUEIRO, 2012). Mas as HQ já vinham saindo aos poucos do submundo mesmo antes desses documentos oficiais, com autores de livros didáticos mais sensíveis a sua utilização, que, a partir de 1970, já inseriam tal ferramenta em seus produtos - claro que sob um olhar ainda desconfiado dos mais conservadores.

Atualmente, mesmo com certo protagonismo, o uso de quadrinhos na educação ainda é pequeno diante das possibilidades. Mas o que era visto como 
prejudicial incitação à criminalidade, causador de preguiça mental, hoje é visto como um potencial recurso didático, com benefícios para as ligações cognitivas e que funcionam de forma lúdica para auxiliar a aprendizagem. Ao pensarmos nas ligações cognitivas, não podemos deixar de citar que essa provavelmente seja a sua principal qualidade, a característica lúdica. É claro que a aprendizagem sempre tem que estar em primeiro plano, mas uma ferramenta que aguce a curiosidade, que funcione como um jogo, que te leva a querer construir ou desvendar, pode se configurar como útil no contexto em que vivemos. Assim flui a ludicidade, como um jogo que envolve, leva o aluno a ir além, a buscar mais. "A ludicidade como prática pedagógica possui um papel importante, relacionado ao despertar autônomo dos interesses por parte do aluno", conforme afirma Testoni (2004, p.37).

Além do aspecto lúdico, os quadrinhos também exercitam, entre outras, a linguística, criatividade, comicidade, motivação, a leitura e a contextualização. São muitas qualidades, mas buscaremos exemplificar essas cinco, além do aspecto lúdico. A linguística é exercitada pelo papel da narrativa, ao criar uma história em quadrinhos, ou mesmo como leitor, o aluno aprende e desenvolve sua língua, sua articulação, sua estética, além de interpretar situações diversas, que dependem de conhecimento de diversas áreas. A criatividade vem na criação dos quadrinhos e também na leitura, quando, ao ler um quadrinho, não se interpreta algo estático, o leitor interage, é coautor da história contada. Os sons, onomatopeias, cenários, fazem que a história crie vida na imaginação do aluno, os balões levam a ouvir as falas como gritos ou sussurros, uma interatividade e criação análoga a que ocorre quando se lê um livro.

Esses espaços vazios, de acordo com Lovreto (1995), são preenchidos pelo que o aluno traz consigo, o que está internalizado, uma narrativa que se conecta com o leitor e o leitor o transforma ao ler. Essa perspectiva se alinha ao modelo mais atual de comunicação que considera o leitor-espectador com papel ativo na produção de sentidos daquilo que lê, se opondo ao modelo tradicional emissor-mensagem-receptor. A comicidade é uma característica mais comum nas charges e tirinhas, muito útil para atrair um leitor iniciante, devido a sua mensagem mais rápida e que normalmente é feita com desenhos mais simples. A motivação à leitura é dada pelas várias qualidades dos quadrinhos, mas, segundo Lovetro (1995), "o impacto visual é sempre a mola que move a vontade de ler um quadrinho". Para esse autor, jornalista e cartunista, em diversos cursos e workshops que desenvolveu pode constatar que o que move alguém a se interessar pelos quadrinhos é o encanto pelo desenho. Mesmo um leitor que não tem muito costume de ler devido à falta de tempo e ao trabalho, acaba seduzido pela facilidade de leitura e a simplicidade gráfica de uma tirinha por exemplo.

Por fim, destacamos a contextualização, que é a principal no âmbito desta pesquisa. É essa característica que possibilita que o aluno, mesmo 
estando na sala de aula, vivencie situações do dia a dia do mundo do trabalho da construção civil, tanto nos escritórios quanto nos canteiros de obras. Essa qualidade pode fazer com que ele traga suas experiências e se conecte com as situações propostas em aula. Suas experiências e sua história enriquecem o desenvolvimento das narrativas. Com esse potencial gigantesco fica difícil compreender que o uso ainda desperte receios, preconceitos, mesmo pelos mais tradicionais. Existe muito material para o destino pedagógico e muito material público. Podemos citar um diretório criado pela Universidade de São Paulo (USP) contendo um catálogo com todos os exemplares publicados no Brasil - um enorme acervo para preservar merecidamente a memória dessa arte.

Para Caruso, Miriam e Silveira (2005), ao relatarem o uso de quadrinhos em seus trabalhos, em uma sociedade que vive impregnada de imagens, a escola deve se aproveitar da comunicação visual para se tornar mais atraente para o aluno. Para eles, por receio ou falta de conhecimento de como fazer, se perde muito ao não utilizar HQs para propiciar à alfabetização científica. Seu uso poderia ser maior se não fosse o receito de alguns educadores, pois seus benefícios aliados ao baixo custo são inegáveis. Hoje, mesmo os quadrinhos estando nas aulas, ela não limita as possibilidades de seu uso na educação. A educação não-formal também é um espaço no qual os quadrinhos vêm sendo cada vez mais utilizados, como em guias para parques e museus, além de materiais educativos voltados à segurança do trabalho e à área de educação em saúde. Como exemplos, o uso dos quadrinhos nas oficinas criadas por Caruso e Silveira (2008) teve a característica de serem histórias diversas criadas pelos alunos, tendo por base uma preparação prévia envolvendo conversas, palestras e visitas externas. Já nos quadrinhos desenvolvidos nas oficinas de Testoni (2004), o professor criou os personagens e o enredo, e os alunos produziram o material e desenvolveram questões relacionadas à física. Nesta pesquisa vislumbramos tangências com esses dois trabalhos ao envolver a elaboração de histórias pelos alunos, que no caso são os storyboards, em uma oficina de tirinhas com personagens previamente definidos, criados pela professora.

O uso de quadrinhos cria uma perspectiva diversa capaz de integrar o formal e 0 não formal, permitindo que um transforme o outro, auxiliando 0 ensino de ciências. Caruso e Silveira (2008) explicam que ao dinamizar as aulas com as oficinas de quadrinhos, observaram tal integração em muitos momentos, quando não só questões ambientais eram tratadas de forma crítica, mas o aluno pode refletir sobre seu entorno, sua escola, os problemas sociais, sua profissão, seu país. Eles também comentam que o uso dos quadrinhos possibilitou a valorização de situações do cotidiano e da vivência das crianças e jovens. Desta forma, tanto as oficinas desenvolvidas por esses autores quanto à desenvolvida no contexto desta pesquisa envolve, além de todas as questões já expostas, a possibilidade de se acreditar e dar espaço para o que traz o aluno, tanto sua realidade quanto seu sonho, o acreditar em uma 
mudança, construindo suas próprias narrativas, suas utopias. "Deixar [...] o gosto pelo sonho, por aquele sonho transformador do próprio homem e de seu entorno. (CARUSO; MIRIAM; SILVEIRA, 2005, p. 34), que envolve os sonhos que perdemos e que só parecem piorar com a crise social, econômica e política em que vivemos intensamente nos últimos anos. Quando os alunos criam suas histórias e mudam suas realidades, eles podem ser capazes de sonhar em possibilidades e momentos melhores, o que nos faz lembrar o documentário sobre jovens estudantes do ensino médio no Brasil intitulado "Nunca me sonharam".

\section{METODOLOGIA}

Esta pesquisa possui caráter qualitativo de abordagem participante, escolhida por propiciar que os alunos, assim como a professora/pesquisadora, fossem sujeitos ativos no processo de pesquisa, o que foi possível devido à própria dinâmica da elaboração das tirinhas pelos alunos. Todo o processo foi planejado previamente para que cada etapa potencializasse a vontade de conhecer a trajetória do outro através da expressão das histórias construídas pelos alunos, o conhecimento a partir de suas vivências particulares, culturais e em comunidade, de forma que fossem levados em conta na construção das histórias nas oficinas.

Assim, os alunos são apresentados a seguir como participantes, protagonistas da pesquisa, passando pelos percursos metodológicos, pelos percursos da prática em sala de aula. A pesquisa foi desenvolvida com uma turma de 10 alunos que cursa a disciplina Projeto Final, que faz parte da matriz curricular do terceiro período do Curso Técnico em Edificações do CVT de Mesquita (último semestre do curso que tem duração de um ano e meio). Todos os tópicos fazem parte do Currículo Mínimo da disciplina em questão (RIO DE JANEIRO, 2011), visto que Projeto Final é uma disciplina que converge os conhecimentos adquiridos ao longo do curso para a elaboração de um projeto arquitetônico completo.

Esse percurso metodológico envolveu uma aplicação piloto da oficina de tirinhas para fins de sua validação, que propiciou, então, um retorno à sala de aula para implementação da oficina com uma turma com seis (6) estudantes. Após a aplicação piloto, mesmo com resultado satisfatório, ocorreram problemas, em geral, relacionados à autoestima, motivação e criatividade. Com isso, dividimos os dias por tipo de prática (aula explanatória, vídeo com debate e produção criativa), acrescentando mais tempo para elaboração dos storyboards e trazendo novas ferramentas criativas para que a imaginação dos alunos pudesse fluir de uma forma livre, menos controlada.

Os produtos educacionais (uma sequência didática e um encarte de tirinhas, apresentados ao final da próxima seção) surgem como resposta aos 
trabalhos desenvolvidos pelos alunos na oficina de tirinhas. Esse percurso metodológico durou um mês e o projeto foi aprovado pelas instituições envolvidas e seguiu todos os preceitos.

\section{OFICINA DE TIRINHAS}

Foi feito um planejamento de quatro dias, sendo um dia de seis aulas para a etapa de apresentação, dois dias com seis aulas cada para trabalhar o conteúdo e, no último dia, um exercício conectando a criação dos enredos dos storyboards com o exercício de criatividade inspirado no Design Thinking (DT). Segundo Reginaldo (2015, p. 93), é um processo prático de cocriação a partir de cinco etapas: descoberta, interpretação, ideação (brainstorming), experimentação (prototipar) e evolução. Trata-se de uma ferramenta baseada na forma de pensar dos designers, em que os desafios de encontrar soluções práticas e que seja viável fazem parte da rotina. Buscou-se, com isso, conseguir que os alunos resolvessem os problemas de forma criativa, coletiva e participativa, criando um link artístico com a criação dos storyboards.

Desta forma, foi elaborada uma sequência didática para quatro dias, iniciando a primeira aula a exibição da animação intitulada "A história das coisas". Na mesma aula, após a exibição do vídeo, realizou-se discussão acerca da sociedade dos dias de hoje, o consumismo e o que impacta nas questões ambientais. Foi apresentado o encarte de tirinhas e os personagens e explicado o que seria proposto ao longo das próximas aulas. No segundo dia, foi escolhida como tema a problemática da infraestrutura sanitária dos municípios da Baixada Fluminense, e, em seguida, foram feitas discussões sobre as questões ambientais envolvidas nos problemas de saneamento urbano, soluções possíveis e o que está sendo feito de certo e de errado. Já no terceiro dia, foi escolhido como tema o problema dos resíduos de pequenas e médias construções e reformas. No quarto e último dia dessa segunda implementação da oficina de tirinhas, foi elaborado um exercício de criatividade com base nos conceitos do DT quando, após a escolha dos enredos, foram construídos os storyboards.

Os materiais didáticos usados na atividade de estímulo à criatividade $\mathrm{e}$ na elaboração dos storyboards foram lápis, borracha, caneta azul, post-its (para a etapa de brainstorming do DT), papel A4, tesoura, cola, tirinhas de gibis sem as falas, impressões dos personagens criados pela professora para utilização de técnica de colagem. Com base no trabalho de Reginaldo (2015), os materiais e vídeos desenvolvidos pelo site www.desingforeducators.com foi adaptado para esta pesquisa, simplificando ao máximo os processos de acordo com o que consideramos necessário para desenvolver a criatividade dos alunos durante a realização da oficina de tirinhas. 
A primeira aula foi feita com a apresentação do vídeo "A história das coisas", e, após a exibição, foi iniciada uma discussão sobre consumismo, sistema capitalista, como somos invadidos com propagandas e seduzidos a consumir cada vez mais, como a indústria da construção civil se comporta e como somos obrigados a consumir os produtos (materiais de construção) que estão disponíveis nas prateleiras, muitas vezes sem opção, e qual a nossa responsabilidade como construtores da região da Baixada Fluminense. Após a discussão, foram apresentados os personagens e tirinhas desenvolvidas com base nos storyboards criados pela turma anterior e também foi apresentado 0 cronograma das atividades a serem realizadas.

O primeiro tema escolhido para revisão e debate sobre as questões ambientais foi o saneamento urbano, devido a sua importância para comunidade. Os pontos importantes que foram discutidos, entre outros, foram:

a) o custo para prefeitura do asfalto e do saneamento básico:

b) como deveria ser feito e como é feito na realidade;

c) o que afeta na qualidade da água;

d) de quem é a culpa dos rios na região terem virado esgoto a céu aberto;

e) onde estão as estações de tratamento de esgoto, e quando existem, porque não funcionam;

f) se ainda é realidade o despejo dos dejetos do coletor público nos rios da região;

g) os rios da Baixada Fluminense que vão para a Baia de Guanabara.

O tema repercutiu muito entre os alunos que puderam rever (pois se trata de uma revisão) pelo olhar crítico das questões ambientais e isso trouxe muita indignação aos alunos, e por se tratar de um assunto muito presente em suas vidas, pois todos moram próximos aos rios e convivem com enchentes e problemas relacionados ao esgoto diariamente. Todos puderam contribuir com reflexões e casos ocorridos.

O segundo assunto escolhido para, revisão e debate, sobre as questões ambientais, foi a gestão de resíduos em pequenas obras. Este tema foi escolhido, pois quando é abordado no momento pertinente do curso ele não foca nas pequenas construções e são elas, as pequenas reformas, feitas por pessoas físicas que são responsáveis pela maior parte dos entulhos (resíduos) do tipo. Em sua maioria são despejados em locais não apropriados. Os pontos importantes que foram discutidos, entre outros diversos, foram:

a) pouco entulho não justifica aluguel de caçamba e onde se deve descartar;

b) como deveria ser feito e como é feito na realidade;

c) o que afeta na qualidade da água;

d) de quem é a culpa dos locais de descarte clandestinos; 
e) onde estão os ecopontos da região;

f) o que acontece com os resíduos depois de descartados;

Esse segundo tema teve muita discussão, mas eles se interessaram, principalmente, pelas informações novas, pois muitos alegaram que não sabiam que as pequenas reformas, aquelas realizadas por pessoas físicas, são responsáveis pela maior parte dos resíduos de obras despejados em locais inapropriados. Outra informação que gerou grande discussão foi sobre o fato de que quase cem por cento (100\%) dos resíduos de uma obra pode ser reaproveitado, e que existem usinas de reciclagem desses produtos, que transformam, por exemplo, restos de concreto e alvenaria em britas que podem ser usadas em partes não estruturais de uma nova obra.

Esse processo criativo foi iniciado tendo como guia os materiais citados acima na breve explicação sobre DT. Primeiramente, buscou-se corrigir deficiências encontradas no primeiro momento da pesquisa, e, para isso, foi destinado previamente dois dias para que exercitassem o debate sobre não só questões ambientais, mas também questões sociais envolvidas nos dois temas abordados.

No início da aula, depois de lembrarmos rapidamente dos temas discutidos anteriormente, partimos para o brainstorming, um momento em que diversas palavras surgem, ideias soltas, sem que nenhum aluno se sentisse censurado ou constrangido por mais simples ou desconexa que pudesse parecer a sua ideia. Nesse momento, eles escreveram em diversos post-its opiniões sobre os assuntos tratados nas aulas anteriores. Todas as ideias foram colocadas lado a lado, como exemplificam as Figuras 2 e 3 a seguir. 
Figura 2: Post-its criados na etapa de ideação (brainstorming)

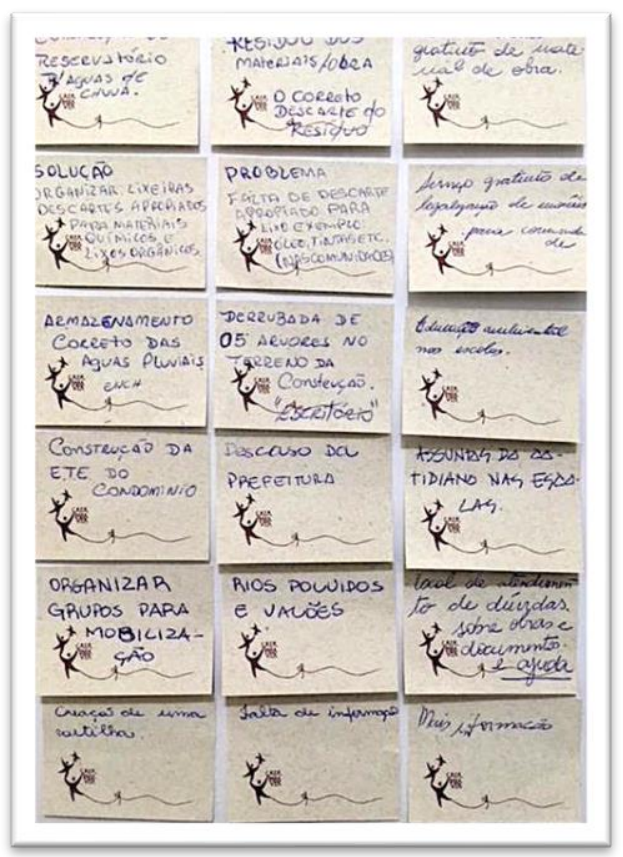

Fonte: Acervo da pesquisa.

Figura 3: Quadro organizador dos post-its.

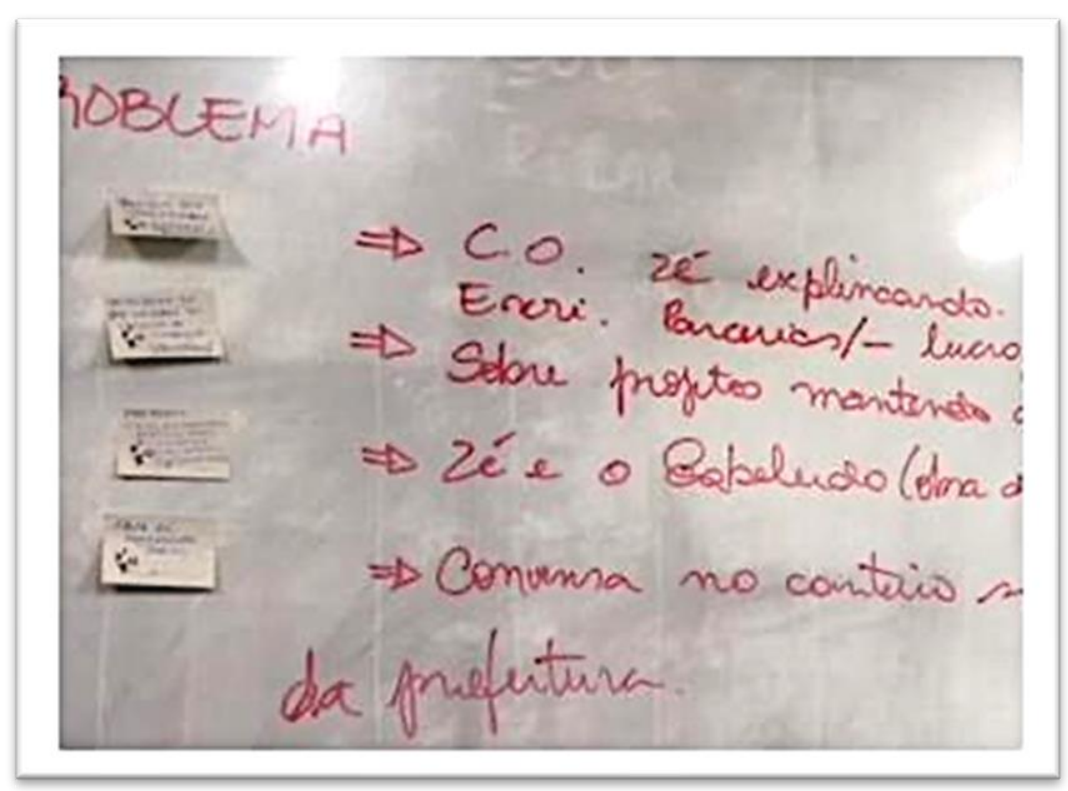

Fonte: Acervo da pesquisa.

Depois disso, a missão foi de reescrevê-las com o máximo de viabilidade, de forma que fossem exequíveis e selecionando os mais populares 
para que avançassem para última etapa, a prototipação, ou seja, a construção dos storyboards. Com isso, foram criadas as tirinhas T1 (Figura 4) e T2 (Figura 5), respectivamente, pelos grupos A e B de estudantes.

Figura 4: Tirinha escolhida pelo Grupo A (T1)

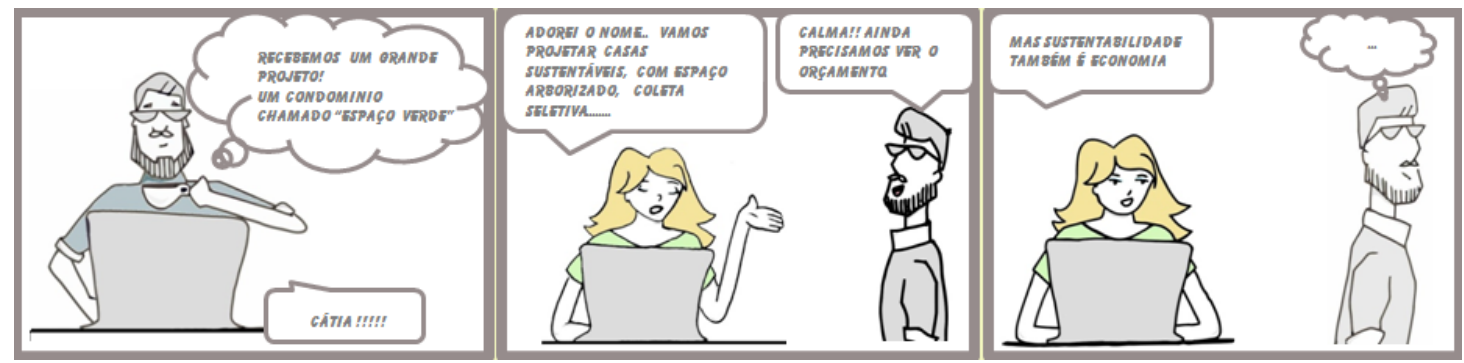

Fonte: Acervo da pesquisa.

A tirinha T1 traz um diálogo entre os personagens Cátia e o seu chefe Fred, em que o assunto abordado foi o de criação de um projeto dito verde em um escritório no momento de seu planejamento, como a viabilidade financeira. Foi bem oportuno esse assunto que o grupo escolheu, pois estavam passando naquele momento pelo desenvolvimento do projeto final deles, e, com isso, estavam refletindo exatamente essas questões de o que inserir em uma construção sustentável e aproveitaram toda discussão que tiveram nas aulas sobre sustentabilidade para criar o enredo.

Figura 5: Tirinha escolhida pelo Grupo B (T2)

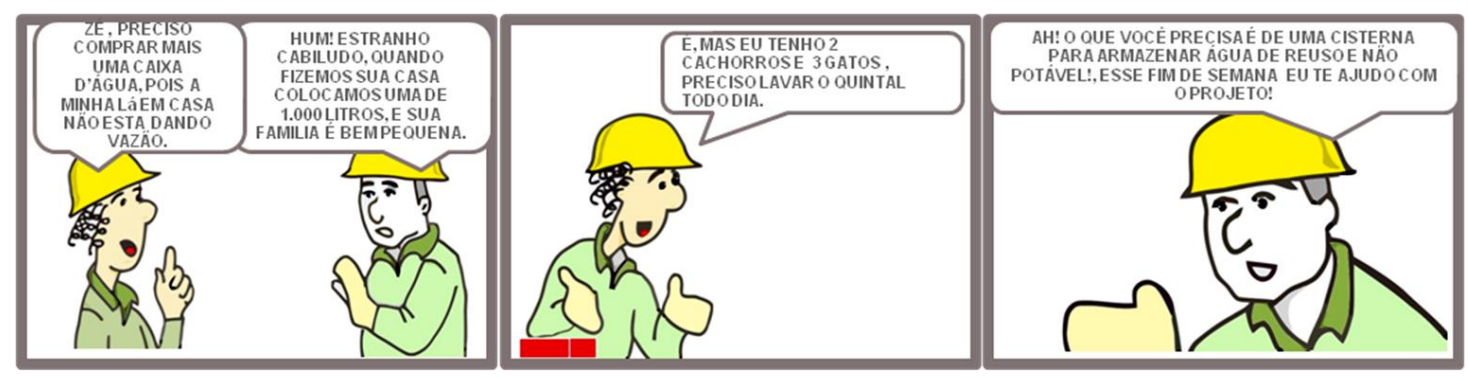

Fonte: Acervo da pesquisa.

A tirinha T2 traz um diálogo entre os personagens Zé e Cabiludo, que acontece em um canteiro de obras, e eles discutem sobre o uso correto da água e planejam um encontro fora do horário de trabalho para projetarem uma melhor solução. Primeiramente o que se observa é o fato de os pedreiros estarem planejando projetar algo, o que é interessante, pois mostra que os 
alunos entendem que em qualquer situação é necessário um projeto do que se almeja fazer. Os alunos conseguiram fazer uma boa relação com o perfil dos personagens e trouxeram informações pertinentes da realidade deles com os assuntos abordados em sala de aula, conseguindo articular os personagens, 0 mundo em que os personagens estão inseridos e a realidade deles com as questões ambientais.

$\mathrm{Na}$ implementação da oficina de tirinhas foram destinados momentos distintos para debates e para a produção criativa das tirinhas. Na produção dos storyboards, os assuntos já estavam definidos, assim como quais personagens estariam no croqui criado. Somado a isso, o fato de terem os desenhos impressos e prontos apenas com uma montagem e colagem, fez com que os alunos ficassem satisfeitos, criando autoestima acerca do material produzido entregue como resultado final.

Figura 6: Exemplos de storyboards criados na oficina de tirinhas

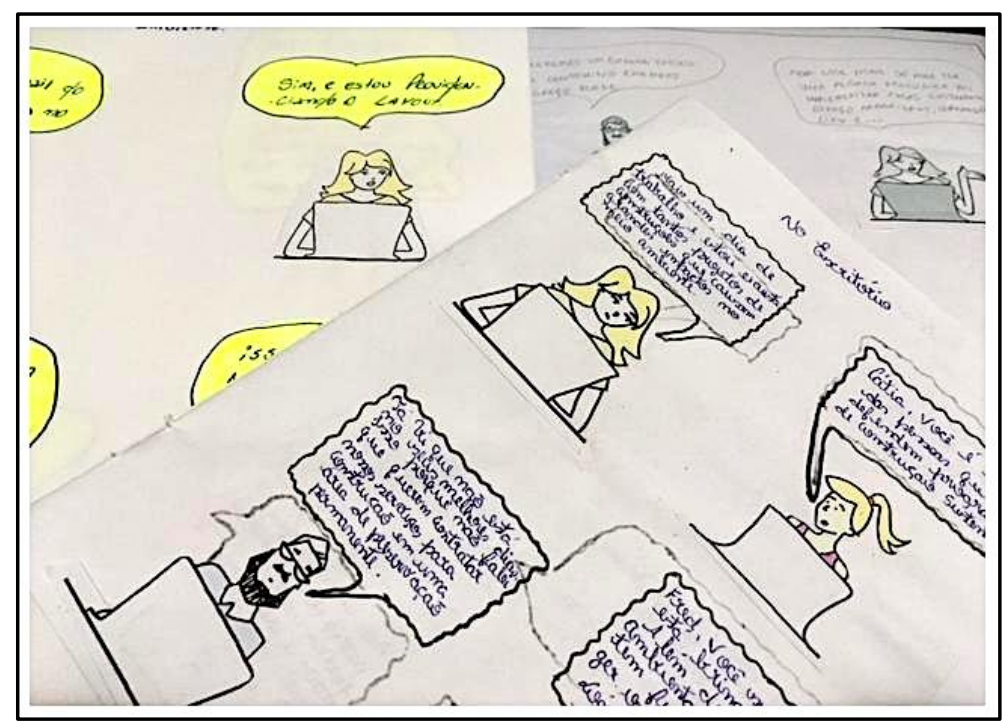




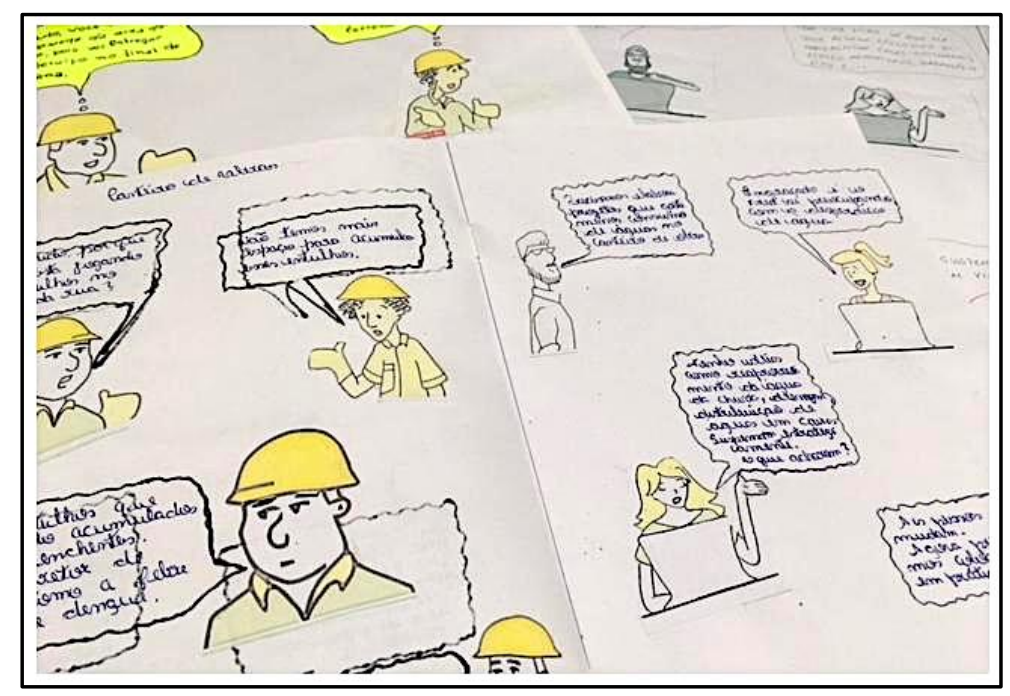

Fonte: Acervo da pesquisa.

Observamos na implementação da oficina problemas relacionados a ansiedade dos alunos em querer entender o processo criativo no meio do caminho, e também o trabalho de planejamento que foi muito maior, mas o que compensou pelo resultado, que deu origem a dois produtos educacionais registrados: a sequência didática utilizada e o encarte de tirinhas.

\section{CONSIDERAÇÕES FINAIS}

Com o trajeto da pesquisa, visualizamos amadurecimento em alguns aspectos. Primeiro, a interpretação do que estava ocorrendo em sala de aula, pois ela era um reflexo do que vivemos e como a sociedade em geral lida com as questões ambientais, de forma simplista e aceitando soluções ditas sustentáveis como única verdade. Outro ponto foi o de entender que na sala de aula também não existe uma postura ou ferramenta que resolverá tudo, que trará a solução para a construção civil. Ouvir a realidade do aluno e planejar a pesquisa e o produto educacional pensando nessa sala de aula foi essencial, uma vez que poderia fracassar se tentasse solucionar problemas mais gerais da educação profissional.

Vale destacar que durante os debates e oficinas foi possível conhecer a história dos alunos e usá-las como matéria-prima para as discussões, pois se no início a intenção era de construir conhecimento, o que ocorreu foi identificar atitudes da realidade desses alunos para utilizá-las como algo genuíno para uma postura sobre as questões ambientais. Nem todos os momentos das discussões foram de otimismo e descontração, falar de separação de lixo doméstico em locais onde nem a coleta de lixo convencional é uma certeza 
parece um pouco cruel. Em muitos momentos, quando interrogados, os alunos voltavam a expressar frases feitas sobre as questões ambientais e isso parecia um retrocesso, mas podemos perceber que há mais do que apenas não estar refletindo de forma crítica. Há um ritual de formalidade para que os alunos queiram responder o que eles acham que o professor quer ouvir em vez do que eles realmente estão pensando.

Por fim, sabemos que a inserção das HQs como contextualização do mundo do trabalho não é novidade, muito menos exclusividade desta pesquisa. Com uma simples busca podemos visualizar diversos trabalhos acadêmicos que se debruçam sobre isso, mas, mesmo lendo sobre todas essas possibilidades e termos construído expectativas e pressupostos sobre seu uso, não poderíamos dimensionar o quão rico seria sua contribuição para a interação dos alunos da educação profissional e o mundo do trabalho relacionando a construção civil e a educação ambiental.

Os desenhos simples das tirinhas foram primordiais, seduziram o aluno desde a primeira aula, e esse interesse se manteve até o momento da construção de seus storyboards, a ponto de se preocuparem com a estética do que estavam produzindo. Esse espaço de criação serviu como uma continuação mais descompromissada das discussões, quando brincadeiras e piadas surgiam em alguns momentos, a ponto de também se transformarem em enredos. Foram momentos de troca e aprendizado. Ouvir o estudante falando da sua vida, muitas vezes fugindo do assunto, acabou unindo ainda mais a turma, como integrantes de uma classe, moradores de uma região de histórias únicas, de esgoto a céu aberto, rios poluídos, falta de respeito dos governantes com a população, escolas abandonadas, com infiltração, sem água, escassez de funcionários, entre outros problemas. O pano de fundo foram as questões ambientais, o assunto da construção civil, e como resultado, muito de cidadania, identidade, educação, respeito, diretos, sonhos e realidade.

Concluindo, uma breve história de um aluno que, nas discussões, sempre trazia seu ponto de vista sobre a construção civil da região onde ele mora e as questões ambientais de forma muito autêntica. Isso nos fez refletir em como um aluno que poderia ser visto como inconveniente era muito mais do que a sala de aula precisava nas discussões. Se para uma aula convencional sua postura poderia ser um empecilho, nesta pesquisa sintetiza o que se busca com uma educação ambiental crítica, uma sustentabilidade democrática, entendendo a vida como uma teia, onde tudo se relaciona. Marcelo (nome fictício), 22 anos, ajudante de pedreiro, se autopromoveu a pedreiro durante sua estada no curso. Falante, estudou sempre em escola pública, reprovado algumas vezes, com um pequeno problema de audição que o atrapalha a ouvir a explicação do professor. Inteligente e inconveniente, gosta de provocar o professor. Morador da região da Baixada Fluminense, tem um pouco de vergonha de falar de si mesmo e de sua família, mas contou que 
frequenta igreja e não bebe, mas que busca a mãe no pagode quando ela demora. Orgulha-se da qualidade do seu serviço braçal e de seus acabamentos delicados. Apresentou um trabalho de projeto final impecável e relatou à professora:

\begin{abstract}
Amo morar na Chatuba, tenho uma mangueira na frente da minha casa, vou de bicicleta trabalhar na casa dos meus clientes que são meus vizinhos, dou garantia do meu serviço, pois não faço de qualquer jeito. Se não sei, procuro saber. Sou forte e novo, gosto de construir e ver pronto, me dá orgulho, mas sou chato com detalhes. Não me sinto menos que ninguém, e não sei porque acham que a felicidade só tem a ver com carro, roupa e mansão.
\end{abstract}

Essa pesquisa não finaliza aqui, pois muitos outros Marcelos estarão nas aulas das próximas turmas em que continuaremos a discutir sobre a construção civil e as questões ambientais relacionadas ao mundo do trabalho de uma forma crítica, além de tudo que envolve viver nessa região do Rio de Janeiro.

\title{
REFERÊNCIAS
}

ACSELRAD, H. Sentidos da sustentabilidade urbana. In: (Org.). A duração das cidades: sustentabilidade e risco nas políticas urbanas. Rio de Janeiro: DP\&A, pp. 27-55, 2001.

BOMFIM, A. M. do. O (sub) desenvolvimento insustentável: a questão ambiental nos Países periféricos latino-americanos. Trabalho Necessário, ano 8, n.10, p.1-18, 2010.

CARUSO, F.; MIRIAM, C.; SILVEIRA, M. C. O. Ensino não formal no campo das ciências através dos Quadrinhos. Ciência e Cultura, v.57, n.4, p.33-35, 2005.

CARUSO, F.; SILVEIRA, M. C. Quadrinhos: uma proposta de releitura de. saberes. In: Encontro de Literatura Infantil e Juvenil - Leitura e Críticas, 5., Rio de Janeiro, 2008. Anais... 2008.

DELUIZ, N.; NOVICKI, V. Trabalho, meio ambiente e desenvolvimento sustentável: implicações para uma proposta de formação crítica. Boletim Técnico do SENAC, v.30, n.2, p.18-29, 2004.

EISNER, W. Comics \& Sequential Art. São Paulo: Martins Fontes, 1989.

FRIGOTTO, G.; CIAVATTA, M. Educar o trabalhador cidadão produtivo ou o ser humano emancipado? Trabalho, Educação e Saúde, n.1, p.45-60, 2003. 
HAAG, C. A nona arte. Revista Pesquisa FAPESP, São Paulo, n.110, p.8688, abr. 2005.

LOUREIRO, C. F. B; LAYRARGUES, P. P. Ecologia política, justiça e educação ambiental crítica: Perspectivas de aliança contra-hegemônica. Trabalho, Educação e Saúde, v.11, n.1, p.53-71, 2013.

LOVRETO, J. A. Quadrinhos - a linguagem completa. Comunicação e Educação, n.94 a 101, jan/ abr. 1995.

RAMA, A.; VERGUEIRO, W. Como usar as Histórias em Quadrinhos na sala de aula. São Paulo: Contexto, 2004.

REGINALDO, T. Referenciais teóricos e metodológicos para a prática do design thinking na educação básica. 206p. Dissertação (Mestrado em Engenharia e Gestão do Conhecimento), Universidade Federal de Santa Catarina, Florianópolis, SC, 2015.

RIO DE JANEIRO. Secretaria de Estado de Ciência, Tecnologia e Inovação. Currículo Mínimo Comum. 2011. Disponível em:

$<$ http://www.faetec.ri.gov.br/index.php/planos-de-curso-medio-tecnico/60ensino-medio-tecnico-integrado>. Acesso em: 09 set. 2020.

SANTOS, R. E; VERGUEIRO, W. Histórias em quadrinhos no processo de aprendizado: Da teoria à prática. EccoS - Revista Científica, n.27, p.81-95, jan./abr. 2012.

TESTONI, L. A. Um corpo que cai. As Histórias em Quadrinhos no ensino de física. São Paulo, 2004. 158p. Dissertação (Mestrado em Educação) Faculdade de Educação, Universidade de São Paulo, 2004.

VERGUEIRO, W; RAMOS, P.: Quadrinhos na educação: da rejeição à prática. São Paulo: Contexto, 2009. 